\title{
DOSSIÊ
}

\section{As características distintivas dos crimes de responsabilidade na tradição republicana brasileira do impeachment}

Almir Megali Netol

Como citar este artigo: NETO, Almir Megali. As características distintivas dos crimes de responsabilidade na tradição republicana brasileira do impeachment. Revista de Ciências do Estado. Belo Horizonte: v. 6, n. 1, 2021, e32803. ISSN: 2525-8036.

Resumo: o objetivo do presente trabalho é recuperar a distinção inaugurada ainda na República Velha entre as tradições norte-americana e brasileira do impeachment. Como fio condutor dessa discussão, adota-se os acórdãos proferidos pelo Supremo Tribunal Federal no julgamento dos habeas corpus n. 4.091 e n. 4.116, respectivamente, nos anos de 1916 e 1918. No primeiro, o Tribunal reconhece a possibilidade do controle jurisdicional do processo de impeachment. No segundo, o Tribunal fixou entendimento segundo o qual compete privativamente à união federal legislar sobre crimes de responsabilidade no Brasil. Em ambos os casos, sob o pano de fundo da natureza política e jurídico-penal do impeachment no Direito Constitucional brasileiro. Por se tratar de pesquisa eminentemente bibliográfica, a metodologia utilizada é a revisão de literatura.

Palavras-chave: Brasil. Estados Unidos da América. Impeachment. Natureza jurídica dos crimes de responsabilidade.

Recebido em 30.03.2021

Aprovado em 26.04.2021

Publicado em 01.05.2021

\section{INTRDOUÇÃO}

De acordo com Cass Sunstein (2017, p. 12), impeachments presidenciais são eventos raros. Para o autor, a raridade de processos de impeachment não seria por si só algo ruim para a vida política de um país. Isso porque, em certo sentido, a raridade de processos tal como este poderia indicar, segundo Sunstein, que os presidentes historicamente desempenham de maneira adequada as suas funções. Por outro lado, porém, o fato do instituto não ser recorrente seria um problema, na medida em que o mesmo não seria objeto de maiores reflexões pela cidadania.

\footnotetext{
${ }^{1}$ Doutorando, Mestre e Graduado em Direito pela Universidade Federal de Minas Ferais (UFMG).
} 
Sendo assim, o professor da Faculdade de Direito da Universidade de Harvard associa o impeachment à espada de Dâmocles (SUNSTEIN, 2017, p. 53). Assim como a espada de Dâmocles, o impeachment sempre alertaria os presidentes da possibilidade de serem removidos do cargo no caso de sérios abusos de poder. Dessa maneira, quando eventualmente a espada de Dâmocles cair sobre a cabeça de um presidente, muito provavelmente não se saberá o que fazer, já que poucas são as reflexões sobre o instituto.

O diagnóstico de Cass Sunstein se aplica perfeitamente ao caso brasileiro. Poucas são as reflexões no campo do Direito Constitucional sobre o instituto. E mais, as raras reflexões que se dedicam a estudá-lo, muitas das vezes, valem-se de uma perspectiva comparada, em especial, da forma pela qual a doutrina norte-americana compreende o instituto a partir da conformação que lhe fora dada pela Constituição de 1787. Por essa razão, é bastante comum observar que os trabalhos brasileiros que se dedicam ao estudo do instituto do impeachment apresentam uma estrutura mais ou menos parecida: iniciam recuperando sua gestação no seio do sistema parlamentar inglês, passam a estudá-lo a partir da sua recepção nos Estados Unidos da América, para somente a partir de então analisar o caso brasileiro, muitas das vezes valendo-se da lente estadunidense. ${ }^{2}$

Tal fato pode ser constatado no decorrer da obra de Paulo Brossard (1992), autor do trabalho mais consagrado sobre o impeachment no país. Mais recentemente, os trabalhos de Rafael Mafei Rabelo Queiroz (2017, p. 220-245) também permitem vislumbrar a influência que a matriz estadunidense do impeachment possui sobre as reflexões realizadas em solo pátrio. Com isso, perde-se de vista elementos essenciais que distinguem a conformação constitucional conferida ao instituto historicamente pelo constitucionalismo brasileiro logo no início do período republicano. O resultado disso são análises que apresentam inconsistências do ponto de vista teórico, posto que omitem elementos importantes de distinção entre as matrizes constitucionais que são abordadas comparativamente. ${ }^{3}$ Além disso, são abordagens que, tal como alertado por Meyer (2018, p. 10), implicitamente a elas, podem expressar o imaginário de uma antidemocrática supremacia da tradição constitucional estadunidense sobre as demais, inclusive, sobre a brasileira. ${ }^{4}$

Não se está com isso afirmando aqui que a matriz constitucional estadunidense ou mesmo a inglesa sejam irrelevantes para fins de estudo sobre o impeachment. Tampouco se

\footnotetext{
2 Para uma recuperação da distinção entre o modelo norte-americano e o inglês do impeachment, Cf. GERHARDT, 1999, p. 905-930.

${ }^{3}$ Para uma crítica nesse sentido, Cf. MEGALI NETO, 2020a.

${ }^{4}$ Para um esforço de repensar a forma pela qual o Direito Constitucional Comparado tem sido trabalhado no Brasil, Cf. MEYER, 2019, p. 479-502.
} 
pretende defender aqui a impossibilidade de estudos comparados sobre o tema. Afinal, é sabido que "a figura do impeachment nasceu na Inglaterra, com forma definida e bem estruturada, dali passando para os Estados Unidos, e, deste país, para o Brasil, onde encontrou clima propício" (CRETELLA JÚNIOR, 1992, p. 14). Portanto, para dizer com José Ribas Vieira e Maria Margarida Lacombe (2016, p. 1), "tanto no corpo da Constituição americana de 1787 quanto no quadro constitucional brasileiro, a adoção do impeachment resultou de um processo de recepção. Os EUA herdaram da Inglaterra e nós dos americanos”.

Dessa maneira, pode-se dizer que o instituto assume traços característicos distintos em cada uma das matrizes constitucionais que o adotaram. Sendo assim, não há problema algum que outras tradições constitucionais imprimam traços característicos próprios ao instituto quando da recepção do mesmo em suas ordens constitucionais. Essas adaptações, por si sós, não fazem dessas experiências constitucionais melhores nem piores, mas, apenas e tão somente, diferentes.

Partindo dessas premissas, o objetivo do presente trabalho é recuperar a distinção inaugurada, ainda na República Velha, entre as tradições norte-americana e brasileira do impeachment. Como fio condutor dessa discussão, adota-se os acórdãos proferidos pelo Supremo Tribunal Federal (STF) quando do julgamento dos habeas corpus n. 4.091 e n. 4.116, respectivamente, nos anos de 1916 e 1918.

No primeiro, o Tribunal reconhece a cognoscibilidade jurisdicional de questões relativas ao processo de impeachment, superando o entendimento anteriormente adotado no sentido da natureza eminentemente política do instituto, para compreendê-lo como um instituto de natureza mista: política e jurídico-penal. No segundo, o STF fixou entendimento segundo o qual competiria privativamente à união federal legislar sobre crimes de responsabilidade, pois, em virtude do caráter misto dessas infrações, os estados-membros não poderiam legislar sobre a matéria, sob pena de invadirem a esfera de competência legislativa privativa reservada à união federal pela Constituição de 1891.

Dessa maneira, torna-se possível vislumbrar como o STF foi capaz de construir uma interpretação dos crimes de responsabilidade que se afasta da matriz constitucional que influenciou sobremaneira os trabalhos constituintes que resultaram na Constituição de 1891, a doutrina jurídica do momento e a própria jurisprudência do Tribunal. No marco da Doutrina Brasileira do Habeas Corpus, que, por si só, já representa uma importante distinção da matriz constitucional brasileira em relação à matriz constitucional norte-americana daquele período, 
o Tribunal foi capaz de reconhecer os dois elementos de distinção entre a tradição republicana brasileira do impeachment e a tradição norte-americana do impeachment.

Esses elementos referem-se a: (i) cognoscibilidade jurisdicional de questões surgidas no decorrer do processo de impeachment sempre que houver lesão ou ameaça de lesão a direito das partes; e (ii) necessidade de observância dos mandamentos da lei especial que define os crimes de responsabilidade e estabelece as regras de processo e julgamento no decorrer de todas as etapas do procedimento. Tudo isso levando em consideração a natureza jurídica mista dessas infrações no constitucionalismo brasileiro, em parte política e em parte jurídico-penal.

A recuperação da formação desse entendimento pelo STF que, aliás, manteve-se no pós-1988 é importante, pois, se não é capaz de por si só evitar que processos de impeachment inconstitucionais e ilegais ocorram, fornece fundamentos para a intuição cidadã voltar-se criticamente contra as práticas e procedimentos institucionais do presente e, por ventura, do futuro, que se distanciem ou se distanciarem das condições necessárias para a deflagração e tramitação de um processo de impeachment legítimo, levando em consideração, para tanto, a perspectiva dos fundadores de um projeto constitucional aberto ao futuro que, apesar de tropeços e retrocessos, é capaz de se autocorrigir nos termos de um processo de aprendizagem social de longo prazo com o Direito e com a política (HABERMAS, 2001, p. 775-776; CATTONI DE OLIVEIRA, 2017).

A relevância de uma discussão tal como a aqui proposta só cresce quando se tem em vista que o impeachment tem se tornado o novo padrão de instabilidade política na América Latina, como bem revelam os estudos do cientista político argentino Aníbal Pérez Liñán (2007). De acordo com o autor, cada vez mais as maiorias políticas da região utilizam o instituto para a deposição de presidentes democraticamente eleitos sem se atentarem para as exigências do Estado de Direito quando da sua deflagração. O instituto teria se transformado, assim, em uma arma utilizada por legislaturas beligerantes para a deposição de presidentes indesejados.

Em sendo assim, o presente trabalho está dividido em duas partes. Inicialmente, será recuperada a forma pela qual o STF reconheceu sua competência para exercer o controle jurisdicional do processo de impeachment no julgamento do habeas corpus n. 4.091 (HC n. 4.091), ocorrido em 1916. Posteriormente, será recuperada a forma pela qual o STF entendeu competir à união federal legislar sobre crimes de responsabilidade sob a vigência da Constituição de 1891, ao julgar o habeas corpus n. 4.116 (HC n. 4.116), em 1918. Como pano de fundo desses julgados, será possível vislumbrar a natureza mista dos crimes de 
responsabilidade no Direito Constitucional brasileiro. Ao final, em sede conclusiva, os argumentos apresentados no decorrer de todo o texto serão recuperados de forma sintética. Por se tratar de pesquisa eminentemente bibliográfica, a metodologia utilizada é a revisão de literatura.

\section{O CONTROLE JURISDICIONAL DO PROCESSO DE IMPEACHMENT NO HABEAS CORPUS 4.091}

Como afirma Pontes de Miranda (1967, p. 356), "a inserção das espécies de responsabilidade no texto constitucional é tradição brasileira, no tocante ao direito material da responsabilização, desde a Constituição de 1824”. Assim o fizeram a Constituição de 1824 em seu artigo 134; a Constituição de 1891 em seu artigo 54, parágrafos $1^{\circ}$ e $2^{\circ}$; a Constituição de 1934 em seu artigo 57, caput; a Constituição de 1937 em seu artigo 85, caput; a Constituição de 1946 em seu artigo 89, parágrafo único; a Constituição de 1967 em seu artigo 84, parágrafo único; a Emenda Constitucional n. 01/69 em seu artigo 82, parágrafo único; e a Constituição de 1988 em seu artigo 85, parágrafo único. ${ }^{5}$ Portanto, a conclusão a que se chega é que, no Direito brasileiro, "sem lei que defina os crimes, não há crime de responsabilidade" (PONTES DE MIRANDA, 1967, p. 374).

Logo no início do período republicano, a grande questão que se colocou frente a essa peculiaridade da tradição brasileira do impeachment, foi a de saber se os estados-membros teriam competência para legislar sobre crimes de responsabilidade de seus presidentes. ${ }^{6}$ Apesar da matéria já estar pacificada no âmbito da jurisprudência do STF no pós-1988, como atesta a súmula n. 722 do STF, posteriormente convertida na súmula vinculante n. 46, importantes lições podem ser tiradas da forma pela qual a controvérsia foi dirimida pelo Tribunal na República Velha, de modo a contribuir para a compreensão da dinâmica instaurada entre os poderes de Estado quando da ativação do instituto nos dias atuais.

Traço característico das nações que adotam o federalismo como forma de Estado é a autonomia dos estados-membros. Nas palavras de Raul Machado Horta (2003, p. 361), “a autonomia do Estado-membro constitui elemento essencial à configuração do Estado federal”. Autonomia esta que, nas palavras do referido autor, refere-se à "revelação de capacidade para

\footnotetext{
5 Para uma recuperação do tratamento conferido pelas ordens constitucionais brasileiras ao instituto do impeachment, Cf. BAHIA; BACHA E SILVA; CATTONI DE OLIVEIRA, 2017, p. 16-32.

${ }^{6}$ Para uma recuperação histórica da atuação do STF nesse período, Cf. CRUZ, 2004, p. 267-283; STRECK, 2018, p. 123-140.
} 
expedir normas que organizam, preenchem e desenvolvem o ordenamento jurídico dos entes públicos" (HORTA, 2003, p. 363).

Pois bem, tratando-se especificamente da autonomia legislativa dos estadosmembros, Lêda Boechat Rodrigues, em a "História do Supremo Tribunal Federal", afirma que "o Supremo Tribunal Federal, em matéria de federalismo, nunca variou seu modo de julgar" (RODRIGUES, 1965, p. 35). De acordo com a autora, que, no volume III de sua obra, dedicase a levantar informações sobre o Tribunal, seus juízes e julgados célebres no período compreendido entre 1910 e 1926, o STF, inspirando-se na prática constitucional norteamericana e nas lições do chief justice John Marshall adotou, desde o início, a premissa segundo a qual, em uma federação, só há um ente dotado de soberania, a união federal. Os estados-membros, por sua vez, teriam apenas autonomia. Nesse período, mais conhecido como o período da Doutrina Brasileira do Habeas Corpus, "a adoção desse princípio pelo Supremo Tribunal Federal mostrou-se muito importante na declaração de inconstitucionalidade de leis estaduais" (RODRIGUES, 1965, p. 35). ${ }^{7}$

Assim se passou no caso do impeachment do então presidente do estado do Mato Grosso, general Caetano de Albuquerque, perante o Congresso Legislativo daquele estado. Albuquerque tomou posse do cargo em 1913, sendo recebido com certo agrado pela população local. Contudo, o clima favorável ao presidente recém-empossado durou pouco, chegando, até mesmo, a se instaurar um conflito armado entre as facções políticas locais daquele estado-membro. Como pano de fundo da desavença política estava interesses econômicos das elites locais relacionados à concessão de vastas porções de terras públicas.

Para se ter uma ideia da tensão política no estado do Mato Grosso, o Congresso Legislativo estadual, alegando coação e pressão do presidente Caetano de Albuquerque, chegou a impetrar um habeas corpus perante o STF para que o Tribunal the assegurasse o direito de reunião sem qualquer interferência do chefe do Poder Executivo local. No sul do estado, um conflito armado havia sido deflagrado e Albuquerque solicitou intervenção de tropas federais para fazer cessar o conflito e, com isso, restaurar a paz e a ordem (RODRIGUES, 1965, p. 299).

Foi o estopim para que o Congresso Legislativo do Estado do Mato Grosso decidisse instaurar um processo de impeachment contra o presidente Caetano de Albuquerque pela prática de cinco crimes de responsabilidade tipificados pela legislação estadual que regulamentava a matéria. É interessante notar algumas manifestações dos atores políticos

\footnotetext{
${ }^{7}$ Para uma recuperação da autonomia dos estados-membros no Direito brasileiro e, em especial, durante o período de vigência da Constituição de 1891, Cf. HORTA, 2003, p. 364-410.
} 
interessados no deslinde deste processo. Como relata Rodrigues (1965, p. 300), "na Câmara Federal, o Deputado Pereira Leite afirmava ser "perigoso o precedente que se quer abrir em Mato Grosso"”. Por sua vez, "no Senado Federal, o Senador Azeredo, rompido com o General Caetano, dizia ser 'o impeachment um processo de natureza política, que não visa à punição de um crime, mas simplesmente afastar do exercício do cargo o Governador que mal gere a coisa pública'". O próprio general Caetano de Albuquerque, no dia do oferecimento da denúncia em seu desfavor, recuperando Thomas Jefferson, dizia que "a tirania dos legisladores seria o perigo mais terrível”.

Nesse cenário político hostil foi impetrado, perante o STF, habeas corpus em favor do presidente do estado do Mato Grosso. Alegava-se que Albuquerque estava sofrendo ameaça de violência e coação, em razão da abertura de processo de impeachment de forma ilegal e por abuso de poder em seu desfavor pelo Congresso Legislativo estadual. Em síntese, as alegações do writ eram no sentido de que (i) tal processo seria inconstitucional; (ii) a assembleia local funcionava de forma ilegal, em razão da ausência da quantidade suficiente de deputados desimpedidos; e (iii) faltaria justa causa para o válido e regular transcurso do processo.

Foi, portanto, nessa oportunidade que o Tribunal "travou a primeira discussão jurisprudencial sobre a natureza do impeachment no direito brasileiro" (HORBACH, 2007, p. 116). Isso porque, até então, o STF já possuía alguns entendimentos no sentido de que questões relacionadas à regularidade dos atos praticados no decorrer de processos de impeachment não poderiam ser levadas à sua jurisdição, já que a matéria se limitaria à economia interna dos Congressos Legislativos estaduais, em razão de sua natureza eminentemente política. ${ }^{8}$ Estava, pois, colocada diante do STF a árdua tarefa de, primeiro, saber se o pedido poderia, ou não, ser conhecido pelo Tribunal para, em seguida, saber se o processo de impeachment instaurado pelo Congresso Legislativo do estado do Mato Grosso violava, ou não, algum direito do paciente.

O ministro Oliveira Ribeiro, relator do $\mathrm{HC}$ n. 4.091, suscitou preliminar para não se conhecer do pedido, por entender ser o impeachment instituto de natureza estritamente política, isto é, instaurado por órgãos políticos que, motivados por razões políticas, resolveriam por termo final ao mandato conferido nas urnas ao chefe do Poder Executivo. Ribeiro fez questão de rememorar a jurisprudência do Tribunal nesse exato sentido em casos anteriores. Nas palavras do ministro Oliveira Ribeiro,

\footnotetext{
${ }^{8}$ Sobre isso, Cf. PINTO, 1992, p. 83-84.
} 


\begin{abstract}
o Supremo Tribunal não deveria conhecer do pedido, porque o impeachment - ou processo do governador do Estado estabelecido na respectiva Constituição estadual, não é um processo crime conforme o nosso direito processual, é sim uma providência política, tomada por uma assembleia política contra uma autoridade por motivos de ordem meramente política - por isso mesmo escapa em absoluto ao conhecimento do Poder Judiciário. Porque assim já resolveu este Supremo Tribunal em face do próprio art. 27 da Constituição de Mato Grosso, que agora está em causa no acórdão unânime de 23 de abril de 1904, de forma que fora relator o honrado ministro Piza e Almeida - o que, aliás, já tinha dito no acórdão de 22 de julho de 1899 o mesmo juiz Piza. E não descubro razão jurídica, ou motivo de ordem constitucional que leva o Supremo Tribunal a alterar sua jurisprudência (Min. Oliveira Ribeiro, voto no HC n. 4.091, p. 1).
\end{abstract}

O ministro Pedro Mibielli acompanhou o voto do ministro relator. Para Mibielli, o pedido sequer deveria ser conhecido, "porque manifesta, clara e nitidamente o caso é fundamentalmente político, e ao Tribunal não cabe competência para conhecê-lo" (Min. Pedro Mibielli, voto no HC n. 4.091, p. 1). Ambos permaneceram vencidos nesta tese.

Logo em seguida, o ministro Pedro Lessa conheceu do pedido. Segundo Lessa, "ficou instituído entre nós o impeachment, não em tudo idêntico ao norte-americano" (Min. Pedro Lessa, voto no HC n. 4.091, p. 1). Dado que em sistemas presidencialistas de governo, o Poder Executivo é independente politicamente do Poder Legislativo, de modo que aquele não depende da confiança política deste para exercer suas funções, Lessa conclui que "o impeachment é uma providência necessária” (Min. Pedro Lessa, voto no HC n. 4.091, p. 1). A partir de então, questiona o ministro: “de que natureza é o impeachment? É na sua essência uma medida constitucional, ou política ou uma medida de ordem penal?” (Min. Pedro Lessa, voto no $\mathrm{HC}$ n. 4.091, p. 1). A resposta veio logo na sequência: o impeachment "é um instituto político, ou de índole constitucional, e por seus efeitos ou consequências, de ordem penal" (Min. Pedro Lessa, voto no HC n. 4.091, p. 1). Assim, para Lessa, "o impeachment, pois, tem um duplo caráter, é um instituto heteróclito” (Min. Pedro Lessa, voto no HC n. 4.091, p. 1).

O ministro Eneas Galvão também conheceu do pedido rejeitando, portanto, a preliminar suscitada pelo ministro Oliveira Ribeiro, relator do caso. Opondo-se à tese de que faltaria jurisdição ao STF para apreciar as questões colocadas nesta demanda por, supostamente, ser o impeachment um instituto de natureza eminentemente política, o ministro Galvão sustentou que a relevância do instituto do impeachment para qualquer sistema jurídico-normativo somente se justifica se o mesmo for manejado de acordo com os ditames legais. Isto é, se as autoridades responsáveis pela condução do feito atuarem dentro dos limites estabelecidos pela ordem jurídica posta e se forem observados os direitos do acusado. Nesse sentido, ao contrário do ministro Oliveira Ribeiro, para quem, o impeachment poderia 
ser motivado por razões de ordem meramente política, o ministro Eneas Galvão sustentou que o instituto somente poderia ser validamente ativado caso o acusado fosse denunciado pela prática de alguma conduta previamente estabelecida pela Constituição e pela lei especial regulamentadora da matéria como apta a justificar a abertura do processo.

O prestígio, a força, a obrigatoriedade de um ato dessa natureza, repousa na presunção de sua conformidade com a lei constitucional, não tem existência legal se é exorbitante das faculdades do poder que o pratica, se não se contém nas suas atribuições e lesa um direito que juridicamente não pode ser atingido por ele. Neste habeas corpus argúi-se a inconstitucionalidade do impeachment, contesta-se esse poder ao legislativo estadual, nega-se a este, ao menos, autoridade para, com a perda do cargo presidencial, declarar a incapacidade do paciente para o exercício de outros cargos, e sob esses aspectos é claro, que ao exame do Tribunal não pode ser subtraído o habeas corpus [...].

Objeto do impeachment são essas faltas, sejam elas ou não crimes previstos no Código Penal, possa ou não delas resultar matéria para o processo criminal perante a autoridade judiciária competente para a imposição das penas declaradas no mesmo código.

Nos termos do art. 54, ns. 1 a 8, da Constituição Federal e de vários dispositivos da lei n. 30, de 8 de janeiro de 1892, não somente infrações de direito penal, mas outros muitos atos contrários ao bom desempenho da função governamental e que não são violação daquela natureza, motivam o impeachment (Min. Eneas Galvão, voto no HC n. 4.091, p. 2-3).

O ministro Guimarães Natal também votou no sentido contrário ao defendido pelo ministro Oliveira Ribeiro. Para Guimarães Natal, o impeachment não teria natureza eminentemente política, como sustentado pelo relator do caso. Em seu voto no HC n. 4.091, Natal foi expresso em dizer que a atribuição de natureza meramente política ao instituto do impeachment seria capaz de desnaturar a forma e o sistema de governo adotados pela Constituição, pois, se assim o fosse, o Poder Executivo estaria subordinado ao Poder Legislativo, de modo que o sistema de freios e contrapesos adotado pela Constituição estaria em risco constante. Isso, contudo, não seria capaz de retirar uma certa carga política que seria própria ao instituto do impeachment, mas, indubitavelmente, conferiria a ele um caráter penal, no sentido de que a remoção do chefe do Poder Executivo deveria estar condicionada aos ditames estabelecidos pela Constituição e pela lei especial regulamentadora da matéria.

O impeachment tal como o consagrou a Constituição Federal nos artigos 53 e 54, não é um processo exclusivamente político, destinado a dirimir os conflitos entre o Executivo e o Legislativo pela privação do mandato do chefe daquele poder, quando, a juízo do Legislativo, seja a sua permanência considerada contrária aos interesses do Estado. Esse caráter exclusivamente político o tornaria incompatível com o regime presidencial, que adotamos, porque entregaria ao arbítrio do Legislativo a estabilidade do Executivo, o que caracteriza o regime parlamentar, que os fundadores da República expressamente condenaram. É também um processo penal e de acentuado caráter judicial: primeiro, porque só poderá ser motivado pela perpetração de um crime definido em lei anterior (art. $54, \S 1^{\circ}$ da Const.); $2^{\circ}$, porque 
a pena a ser aplicada no impeachment não é somente a da privação do cargo, mas também a da incapacidade para exercer qualquer outro (art. 33, $\S 3^{\circ}$.); terceiro, porque é julgado pelo Senado como Tribunal de Justiça nos claros e expressos termos do $\S 1^{\circ}$ do art. 33 da Constituição (Min. Guimarães Natal, voto no HC n. 4.091, p. 4).

A ordem requerida no $\mathrm{HC}$ n. 4.091 foi denegada pelo STF, que, apesar de ter conhecido do pedido, entendeu não haver constrangimento ilegal a ser sanado pelo writ, já que o procedimento adotado pelo órgão legislativo local seria compatível com a Constituição de 1891. É que de acordo com o art. 63, da Constituição, os estados-membros deveriam regerse pelas constituições e leis que adotassem observados os princípios constitucionais da união. Em sendo assim, o impeachment, uma vez adotado pelo artigo 27, da Constituição do estado do Mato Grosso, e contando com regulamentação em nível de legislação especial daquele estado, não poderia proporcionar, segundo a maioria formada neste caso, qualquer constrangimento ilegal ao paciente. Eis a ementa do acórdão:

\footnotetext{
O direito do impeachment é conferido aos Estados pelo artigo 63 da Constituição da República, quando diz que "estes se regerão pela Constituição e leis que adotarem, respeitados os princípios constitucionais da União". A União consagra o impeachment no artigo 58 da mesma Constituição política. O processo a que responde o paciente está estabelecido no artigo 27 da Constituição de Mato Grosso; isto posto, sendo incontestável a competência da Assembléia Legislativa de Mato Grosso para processar o paciente na qualidade de presidente do Estado por fatos que os citados artigo 27 e leis especiais do Estado qualificam de crime de responsabilidade, é evidente que qualquer constrangimento daí resultante contra o paciente não pode dar lugar ao habeas corpus com fundamento no artigo 72, § 22 , da Constituição Federal, que se refere à coação por ilegalidade ou abuso de poder (HC n. 4091, p. 1).
}

Como se viu, a possibilidade de controle jurisdicional do processo de impeachment está diretamente relacionada à compreensão sobre a natureza jurídica do instituto. Nesse sentido, pode-se dizer que "a problemática acerca da definição da natureza jurídica do impeachment é o que justifica ou não o controle, e o modo de controle, pela jurisdição constitucional" (BAHIA; BACHA E SILVA; CATTONI DE OLIVEIRA, 2017, p. 29). Mesmo tendo o STF proclamado a natureza jurídica mista dos crimes de responsabilidade, a posição defendida preliminarmente pelos ministros Oliveira Ribeiro e Pedro Mibielli no HC n. 4.091ainda repercutem na doutrina e também repercutiram no STF no pós-1988.

No âmbito doutrinário, é interessante notar a semelhança do entendimento de Paulo Brossard com a posição de Ribeiro e Mibielli. Em seu estudo monográfico sobre o tema, Paulo Brossard sustenta a natureza estritamente política do instituto e chega a afirmar que "o impeachment tem feição política, não se origina senão de causas políticas, objetiva resultados políticos, é instaurado sob considerações de ordem política e julgado segundo critérios 
políticos" (PINTO, 1992, p. 76). Com base nesse entendimento, ainda segundo Paulo Brossard, "na sua instauração, na sua condução e na sua conclusão, o impeachment terá inspiração política, motivação política, estímulos políticos. Políticos serão os resultados perseguidos. É natural que seja assim; dificilmente assim não será” (PINTO, 1992, p. 182). Por essas razões, sustenta o autor não ser cabível o controle jurisdicional do feito.

Coerente com a sua posição doutrinária, Paulo Brossard, enquanto Ministro do STF, manteve-se fiel e, importante dizer, vencido, na sua posição segundo a qual o impeachment seria instituto essencialmente político em todas as oportunidades nas quais o STF teve novamente essa questão diante de si, logo nos primeiros anos de vigência da Constituição de 1988. Caso a tese sustentada por Brossard prevalecesse perante o Tribunal, esse entendimento deixaria os rumos políticos da noção à sorte das maiorias políticas eventuais, pois,

\begin{abstract}
se os motivos para a instauração e o julgamento são realizados por meio de juízo de natureza essencialmente política, então deverá o Supremo Tribunal Federal se abster de realizar qualquer controle do referido processo e, ainda, não haverá as garantias jurídicas de natureza penal, como a legalidade, o devido processo legal, a ampla defesa e o contraditório (BAHIA; BACHA E SILVA; CATTONI DE OLIVEIRA, 2017, p. 28).
\end{abstract}

No debate constitucional norte-americano, o entendimento majoritário é no sentido de que o Poder Judiciário não teria nenhum papel a desempenhar no curso do processo de impeachment. ${ }^{9}$ Apenas o Poder Legislativo, responsável pela condução do feito, e o Poder Executivo, representado pela figura do presidente acusado da prática de alguma impeachable offense participariam da cena. Charles Black (1974, p. 63), um dos autores mais influentes sobre o estudo do instituto naquele país, chega a afirmar que a regra mais importante sobre o impeachment seria justamente aquela que diz que os tribunais não exerceriam qualquer função durante o processo de responsabilização política do chefe do Poder do Executivo pelo Poder Legislativo. Por outro lado, há vozes minoritárias no sentido da possibilidade desse controle. Raoul Berger (1973, p. 301), outro importante expoente da doutrina estadunidense do impeachment, sustenta que se não existe previsão constitucional para o controle jurisdicional desse processo seria preciso inventá-lo. Para o autor, seria desarrazoado supor que qualquer pessoa pudesse recorrer ao Judiciário contra uma multa de vinte dólares, mas não pudesse

\footnotetext{
${ }^{9}$ No entanto, vale destacar que, durante a Convenção da Filadélfia, os primeiros esboços da Constituição norteamericana atribuíam a competência para processar e julgar o impeachment aos órgãos do Poder Judiciário, pois, como atestam os escritos de Alexander Hamilton no artigo 65 de "O Federalista", acreditava-se que essa função teria nítido caráter jurisdicional. Ao ser transferida para o Senado, essa competência não perdeu seu caráter judicialiforme, conforme anota Charles Black (1974, p. 10). Para uma recuperação desse debate e das razões que motivaram a transferência da competência para processo e julgamento do impeachment do Poder Judiciário para o Senado, em língua portuguesa, Cf. MEGALI NETO, 2020a.
} 
socorrer-se à jurisdição constitucional para se proteger de um processo de impeachment inconstitucional.

Importa dizer que a Suprema Corte estadunidense parece inclinar-se para a defesa da posição sustentada por Charles Black, já que em 1993 relegou o tema à doutrina das questões políticas quando instada a se manifestar sobre a regularidade do procedimento adotado quando do julgamento do juiz federal Walter Nixon pelo Senado norte-americano. ${ }^{10}$ No STF, o debate instaurado doutrinariamente entre Charles Black e Raoul Berger foi recuperado no pós-1988 pelos ministros Sepúlveda Pertence e Paulo Brossard no julgamento da questão de ordem no MS n. $21.564^{11}$ e também pelos ministros Carlos Velloso e Paulo Brossard no julgamento do MS n. 21.689. ${ }^{12}$ De todo modo, diferentemente do que se passa nos Estados Unidos da América, no Brasil, historicamente, desde o julgamento do HC n. 4.091, a jurisprudência do STF se firmou no sentido da possibilidade do controle jurisdicional do processo impeachment.

\section{A COMPETÊNCIA DA UNIÃO FEDERAL PARA LEGISLAR SOBRE CRIMES DE RESPONSABILIDADE NO HABEAS CORPUS 4.116}

Em 1918, o STF julgou o HC n. 4.116, novamente impetrado em favor do general Caetano de Albuquerque. Nessa nova impetração, conforme anota Lêda Boechat Rodrigues (1965, p. 306), "a petição foi assinada pelo advogado Astolfo de Rezende, que alegou estar o paciente, General Caetano, ameaçado de violência". Segundo a autora, assim como o HC n. 4.091, o HC n. 4.116 foi impetrado "contra o processo de responsabilidade que move a Assembleia do Estado de Mato Grosso, a fim de destituí-lo das altas funções que exerce" (RODRIGUES, 1965, p. 306).

Alegava-se que "está na consciência de toda gente que o Presidente do Estado do Mato Grosso é vítima de uma medida inconstitucional da Assembleia do Estado para destituílo do cargo que ocupa". O writ estava fundamentado sob as seguintes premissas: (i) "inconstitucionalidade do processo"; (ii) "funcionamento ilegal da Assembleia"; e (iii) "falta de justa causa da Lei do Estado do Mato Grosso” (RODRIGUES, 1965, p. 306).

A maioria formada no julgamento do $\mathrm{HC}$ n. 4.116 entendeu que deveria haver um paralelismo entre a maneira pela qual os crimes de responsabilidade e suas respectivas regras

10 Trata-se do caso Nixon v. United States, 506 U.S. 224 (1993). Para uma recuperação, em perspectiva comparada, do entendimento alcançado pela Suprema Corte norte-americana em relação ao controle jurisdicional do processo de impeachment naquele país, com o entendimento jurisprudencial do STF em relação à matéria, Cf. FALCÃO, 2002.

${ }^{11}$ Cf. BRASIL, 1996, p. 77-84 e p. 84-94.

${ }^{12}$ Cf. BRASIL, 1996, p. 312-315 e p. 338-345. 
de processo e julgamento são definidos pela união federal e o processo e julgamento dos crimes de responsabilidade nos estados-membros. Nesse sentido, formou-se uma corrente majoritária no sentido de que a lei estadual mato-grossense que regulamentava o processo e julgamento de impeachment naquela unidade federativa e que definia os crimes de responsabilidade seria inconstitucional, pois, o Congresso Legislativo local havia invadido a competência privativa da união federal para legislar sobre direito penal. Abaixo, colaciona-se a ementa do acórdão:

Conhece-se originariamente do pedido de habeas corpus, porque, importando seu
deferimento uma restrição à ordem de habeas corpus anteriormente concedida à
Assembléia Legislativa do Estado de Mato Grosso, garantindo o livre exercício de
suas funções constitucionais, entre as quais está a de processar o presidente do
Estado, tal restrição não poderia ser feita pelo juiz da primeira instância, mas só pelo
próprio Tribunal. O impeachment, na legislação federal, não é um processo
exclusivamente político, mas um processo criminal de caráter judicial. Daí resulta:
primeiro, que os Estados não podem legislar sobre os casos de impeachment, porque
é necessário que estes assumam a figura jurídica de crime e o definir crimes é
atribuição privativa do Congresso Nacional; segundo, que, no processo do
impeachment, dever-se-á conformar com os princípios constitucionais da União,
assegurando ao acusado a mais ampla defesa com todos os recursos e meios
essenciais a ela; terceiro, que a lei estadual de Mato Grosso, em virtude da qual foi
instaurado o processo ao paciente, é inconstitucional, por ter definido os casos de
impeachmente alterado e modificado o Código Penal, lei substantiva, e ainda por ter
no processo se afastado dos moldes da Constituição Federal (Min. Guimarães Natal
voto HC n. 4.116, p. 1).

Um anúncio deste novo entendimento adotado pelo STF em 1918 talvez tenha sido feito pelo voto do ministro Guimarães Natal, ainda quando do julgamento do HC n. 4.091. Naquela oportunidade, Natal ficou vencido no ponto segundo o qual a legislação estadual que define os crimes de responsabilidade e estabelece as regras de processo e julgamento deveria necessariamente observar as disposições da Constituição de 1891, em especial, a regra do seu artigo $34, \S 23$, que conferia à união competência privativa para legislar sobre direito penal.

Isso não quer dizer, como já dito anteriormente, que o ministro Guimarães Natal compreendia os crimes de responsabilidade como meros crimes comuns. Pelo contrário, Natal os compreendia como um misto político e jurídico-penal assim como, por exemplo, Pedro Lessa e Eneas Galvão. Porém, para Natal, em virtude do caráter em parte penal dos crimes de responsabilidade, estes deveriam ser definidos pela união federal que, por sua vez, também deveria definir as penas aplicáveis em tais casos. Em sendo assim, veja-se abaixo trecho do voto proferido pelo ministro Guimarães Natal no HC n. 4.091:

Poderiam os Estados adotar esse instituto nas respectivas Constituições? Sem dúvida, mas com esse caráter de processo judicial e nos moldes, porque, do contrário, violariam a proibição contida no art. 63 da Constituição Federal. Essa 
competência, porém, dos Estados está sujeita a uma restrição, qual a estabelecida pelo art. $34 \S 23$ da Constituição Federal, que declara da atribuição privativa do Congresso Nacional definir crimes e editar penas (Min. Guimarães Natal voto no HC n. 4.091, p. 4).

Com base nos entendimentos firmados no julgamento dos habeas corpus n. $4.091 \mathrm{e} n$. 4.116, extraem-se duas importantes lições que distinguem a tradição republicana brasileira do impeachment da tradição norte-americana que serviu de inspiração para a Constituição de 1891. Trata-se da compreensão segundo a qual os crimes de responsabilidade possuem natureza jurídica mista, isto é, política e jurídico-penal e que, em virtude disso, é possível o controle jurisdicional do processo de impeachment, sendo exigida, ainda, lei especial federal que defina os crimes de responsabilidade, bem como as regras de processamento e julgamento.

A preocupação, portanto, àquele tempo, era a de preservar a forma de governo republicana e o sistema de governo presidencialista, por meio do sistema de freios e contrapesos adotado pela Constituição. Esse ideal foi recuperado pelo ministro Guimarães Natal, na parte final do seu voto no HC n. 4.091, quando de maneira extremamente feliz afirmou que "o regime republicano não periga somente quando uma Assembleia Legislativa se sente coacta, periga também quando uma Assembleia pretende afastar do poder sem razões legais que o justifiquem um Presidente".

É possível constatar certa similitude entre a afirmação de Guimarães Natal acima citada e a intenção dos pais fundadores ao adaptar o instituto do impeachment da monarquia parlamentar britânica para a república presidencialista estadunidense. Da leitura dos registros da Convenção da Filadélfia, bem como dos artigos de "O Federalista", constata-se que a preocupação em relação ao desenho institucional do impeachment estava, desde os primórdios, relacionada à necessidade de garantia do princípio da separação dos poderes e do sistema de freios e contrapesos por ele instituído. Isso seria fundamental para que se pudesse construir uma república, compreendida como espaço destinado à vivência das liberdades. ${ }^{13}$

Não é por outra razão que Cass Sunstein (2017, p. 12-13) afirma ser impossível compreender adequadamente a recepção do instituto do impeachment pela Constituição norteamericana sem recorrer às suas origens na Revolução. Para o autor, os pais fundadores temiam a figura de um Rei. Por sua vez, também seria preciso assegurar ao presidente autonomia em relação ao Congresso para que ele pudesse desempenhar suas funções de maneira adequada. Eles estavam claramente preocupados com a possibilidade de exercício do poder político de maneira arbitrária. Pouco importava se o arbítrio seria produto das mãos de

\footnotetext{
${ }^{13}$ Para uma recuperação desses debates, Cf. MEGALI NETO, 2020a.
} 
apenas uma pessoa, como o monarca absoluto, ou se seria produto das mãos de várias pessoas, como se passou com os corpos legislativos locais no período pós-independência.

Se nos artigos 65 e 66 de "O Federalista", Alexander Hamilton faz uma defesa do modelo constitucional do impeachment, nos artigos 47 a 51, James Madison apresenta uma visão geral sobre a distribuição de funções aos poderes constituídos feita pela Constituição. De acordo com Sanford Levinson (2015, p. 191), no artigo 51 de "O Federalista", Madison faz uma das mais importantes discussões sobre a separação de poderes. Para referido autor, se alguém optar por ler apenas alguma parte da obra, certamente, o artigo 51 deverá ser incluído na lista de leitura. $\mathrm{O}$ argumento central deste ensaio que, em verdade, serve como uma síntese dos fundamentos utilizados por toda cadeia de textos anteriores a ele sobre a mesma matéria (artigos 47, 48, 49 e 50 de "O Federalista"), reside na afirmação de Madison segundo a qual

Se os homens fossem anjos, nenhum governo seria necessário. Se os anjos
governassem os homens, nem controles externos nem internos seriam necessários.
Ao estruturar um governo que deve ser administrado por homens e que deve ser
exercido sobre os homens, aqui está a grande dificuldade: você deve primeiro
permitir que o governo controle os governados; e, em seguida, obrigá-lo a se
controlar (MADISON, 2008, p. 257). ${ }^{14}$

Daí a crença no sentido de que a garantia do princípio da separação dos poderes seria fundamental para a fundação de um Estado no qual os poderes constituídos desempenhariam suas funções de uma forma limitada, moderada e racional e os cidadãos teriam assegurados os seus direitos mais fundamentais. Seria, portanto, o sistema de freios e contrapesos um elemento indispensável para a construção de uma república na qual fosse possível o exercício das liberdades.

Os excessos de poder e o ambiente político conturbado da Primeira República forneceram terreno fértil para a criação da Doutrina Brasileira do Habeas Corpus, tida pela historiadora Lêda Boechat Rodrigues, como "a maior criação jurisprudencial brasileira" (RODRIGUES, 1965, p. 17). Para referida autora, essa jurisprudência criativa teria sido capaz de elevar "o Supremo Tribunal Federal ao nível das mais altas Cortes Judiciárias do mundo, até sobrepujando-as neste particular" (RODRIGUES, 1965, p. 21).

As razões do momento, segundo a autora, exigiram uma atuação jurisdicional mais responsável por parte da Suprema Corte do país com a garantia de direitos fundamentais, a ponto de não se tolerar violações a direitos fundamentais que não pudessem ser reparadas

\footnotetext{
14 Tradução livre de: "If men were angels, no government would be necessary. If angels were to govern men, neither external nor internal controls on government would be necessary. In framing a government which is to be administered by men over men, the great difficulty lies in this: you must first enable the government to control the governed; and in the next place oblige it to control itself" (MADISON, 2008, p. 257).
} 
pelos instrumentos processuais disponíveis. Diante da ausência de remédios constitucionais destinados à tutela dos direitos fundamentais, a solução foi expandir as hipóteses de cabimento do habeas corpus para além dos casos de lesão ou ameaça de lesão à liberdade de locomoção. A partir de então, a ilegalidade e o abuso de poder que colocassem em risco o exercício dos direitos fundamentais do indivíduo ensejaria o cabimento do writ $^{15}$ Isso se tornou possível a partir da redação conferida ao artigo 72, § 22, da Constituição de 1891, segundo o qual: "dar-se-á o habeas corpus, sempre que o indivíduo sofrer ou se achar em iminente perigo de sofrer violência ou coação por ilegalidade ou abuso de poder”.

Em discurso proferido no Senado Federal sobre a Doutrina Brasileira do Habeas Corpus, no dia 22 de janeiro de 1915, Rui Barbosa deu o tom da extensão conferida ao remédio heróico pela jurisprudência do STF, confira-se:

\begin{abstract}
A definição do habeas corpus na Constituição vigente é esta: "Dar-se-á o habeas corpus, sempre que o indivíduo sofrer ou se achar em iminente perigo de sofrer violência ou coação por ilegalidade ou abuso de poder". Não se fala em prisão, não se fala constrangimentos corporais. Fala-se amplamente, indeterminadamente, absolutamente em coação e violência; de modo que, onde quer que surja, onde quer que se manifeste a violência ou a coação, por um desses meios, aí está estabelecido o caso constitucional do habeas corpus.

Coação, definirei eu, é a pressão empregada em condições de eficácia contra a liberdade de um direito, qualquer que esse seja. - E violência? Violência é o uso da força material ou oficial, debaixo de qualquer uma das duas formas, em grau eficiente para evitar, contrariar ou dominar o exercício de um direito.

Logo, srs. senadores, o habeas corpus hoje se estende a todos os casos de constrangimento corporal; o habeas corpus hoje se estende a todos os casos em que um direito nosso, qualquer direito, estiver ameaçado, manietado, impossibilitado no seu exercício pela intervenção de um abuso de poder ou de ilegalidade (RODRIGUES, 1965, p. 141).
\end{abstract}

Segundo aponta Rodrigues (1965, p. 33), a Doutrina Brasileira do Habeas Corpus se deve muito mais ao gênio do ministro Eneas Galvão do que de Pedro Lessa. É que para Pedro Lessa, o habeas corpus somente poderia ser expandido para tutela de outras liberdades quando a liberdade de locomoção fosse condição indispensável para o exercício dessas outras liberdades. Ou seja, "dentro dessa concepção que atrelava o habeas corpus à liberdade de locomoção, Pedro Lessa era contrário à extensão exagerada de sua utilização contra todo e qualquer ato lesivo do Poder Público" (HORBACH, 2007, p. 79).

Por sua vez, Eneas Galvão sustentava a necessidade de expansão do writ a todos os casos nos quais, por ilegalidade ou abuso de poder, as liberdades individuais fossem lesadas ou estivessem ameaçadas de lesão. Galvão sustentava que os sucessivos ataques à liberdade

\footnotetext{
15 Para uma recuperação da criação da Doutrina Brasileira do Habeas Corpus pela jurisprudência do STF, Cf. RODRIGUES, 1965, p. 29-41.
} 
individual justificariam a ampliação do habeas corpus pela jurisprudência do STF que, ao fazê-lo, estaria, na verdade, "cumprindo a sua missão de tutelar direitos, está evoluindo com as necessidades de justiça; se há excesso, é o excesso que leva ao caminho da defesa das liberdades constitucionais" (RODRIGUES, 1965, p. 34).

Nesse período de consolidação da República, a influência do sistema constitucional norte-americano foi inegável, não apenas no Brasil, como em todo o continente. Como afirma George Billias (2009, p. 105), quando o Brasil se tornou uma República, com a promulgação da Constituição de 1891, nenhuma outra região do planeta fazia uso tão expressivo das instituições que compõem o constitucionalismo norte-americano. Assim como a Constituição argentina de 1853, a Constituição de 1891 foi uma das mais influenciadas pelo constitucionalismo norte-americano (BILLIAS, 2009, p. 136). ${ }^{16}$

Rui Barbosa, um dos autores intelectuais da Constituição de 1891, dizia que os Estados Unidos da América seriam o único modelo constitucional a servir de inspiração para o Brasil (BILLIAS, 2009, p. 138). Nesse mesmo sentido, Pedro Lessa, para quem, a escassa doutrina jurídica pátria e a jurisprudência ainda incipiente e vacilante dos tribunais brasileiros o forçaram a recorrer à doutrina e à jurisprudência dos Estados Unidos da América, país que serviu de inspiração para as nossas instituições (LESSA, 2003, p. 1). No plano jurídiconormativo, por exemplo, o artigo 386, do Decreto n. 848/1890, que organizava a Justiça Federal da incipiente República dispunha que "os estatutos dos povos cultos e especialmente os que regem as relações jurídicas na República dos Estados Unidos da América do Norte, os casos de common law e equity, serão também subsidiários da jurisprudência e processo federal". Não é de se espantar, portanto, a constatação de que, nos primeiros anos de vigência da Constituição de 1891, "a citação de autores norte-americanos e da jurisprudência da Suprema Corte dos Estados Unidos é frequentíssima e, em mais de um caso, chega-se a inserir nas ementas dos acórdãos brasileiros" (RODRIGUES, 1965, p. 35).

Isso, contudo, não foi um obstáculo para que, logo naquele período, a jurisprudência do STF se distinguisse em aspectos relevantes da jurisprudência da Suprema Corte norteamericana. Exemplar nesse sentido é a própria Doutrina Brasileira do Habeas Corpus. Assim, "guiados inicialmente pelo gênio de Ruy Barbosa, os juízes brasileiros, na verdade, viram-se diante de uma terra ignota. Em lugar de buscar exemplos na Inglaterra ou nos Estados Unidos tiveram de lançar mão dos seus próprios recursos intelectuais e de sua imaginação criadora" (RODRIGUES, 1965, p. 44).

16 Sobre a influência do constitucionalismo norte-americano sobre a experiência constitucional argentina e brasileira nesse período, Cf. LYNCH, 2012, p. 149-169. 
No caso do impeachment do general Caetano de Albuquerque isso parece ser inquestionável. O STF se reconheceu competente para exercer o controle jurisdicional de constitucionalidade de processos de impeachment; reconheceu a natureza política e jurídicopenal do instituto no sistema constitucional brasileiro; e, em virtude da natureza mista dos crimes de responsabilidade, afirmou ser necessária lei especial federal que os defina. Isso ficou claro logo no julgamento do HC n. 4.091, quando o ministro Pedro Lessa afirmou em seu longo voto que "o impeachment do nosso direito constitucional não é absolutamente o mesmo do direito constitucional norte-americano" (RODRIGUES, 1965, p. 302).

Como aqui já visto, durante o período republicano, todos os textos constitucionais brasileiros encarregaram à lei especial a definição dos crimes de responsabilidade, bem como a determinação das suas regras de processo e julgamento. Tal circunstância é uma singularidade da tradição republicana brasileira do impeachment em relação à matriz estadunidense que lhe serviu de inspiração. Ali, apenas traição, suborno e outros crimes graves e contravenções são suficientes para deflagrar um processo de impeachment. Nenhuma legislação infraconstitucional define as impeachable offenses. Tampouco o procedimento a ser seguido pelas casas congressuais.

$\mathrm{Na}$ trilha da doutrina de Joseph Story, boa parte da doutrina constitucional estadunidense entende ser desnecessária uma legislação encarregada dessas tarefas. Para referido autor, "as ofensas políticas são de caráter tão variado e complexo, tão difíceis de serem definidas ou classificadas, que a tarefa de elaboração de uma lei que as especificasse seria impraticável, se não absurda" (STORY, 1833, p. 264). ${ }^{17}$ Joseph Story (1833, p. 267) afirma que "o Congresso adotou, sem hesitação, a conclusão de que nenhuma lei anterior é necessária para autorizar a instauração de um processo de impeachment; as regras de processo e julgamento são regidas pelas doutrinas do common law e pela prática parlamentar". ${ }^{18}$ Assim, segundo o próprio autor, “o que são e o que não são os 'outros crimes graves e contravenções' deve ser apurado a partir do socorro às bases da jurisprudência norte-americana" (STORY, 1833, p. 267). ${ }^{19}$ Por isso, Michael Gerhardt (2018, p. 61-62) afirma que as impeachable offenses seriam definidas caso a caso pelo Congresso.

\footnotetext{
17 Tradução livre de: "political offenses are of so various and complex a character, so utterly incapable of being defined, or classified, that the task of positive legislation would be impracticable, if it were not almost absurd to attempt it" (STORY, 1833, p. 264).

18 Tradução livre de: "Congress have unhesitatingly adopted the conclusion, that no previous statute is necessary to authorize an impeachment for any official misconduct; and the rules of proceeding, and the rules of evidence, as well as the principles of decision, have been uniformly regulated by the known doctrines of common law and parliamentary usage" (STORY, 1833, p. 267).

19 Tradução livre de: "what are, and what are not high crimes and misdemeanors, is to be ascertained by a recurrence to that great basis of American jurisprudence" (STORY, 1833, p. 267).
} 
Laurence Tribe e Joshua Matz recordam que a expressão "outros crimes graves e contravenções" foi inserida no Artigo II, Seção 4, da Constituição, para permitir que o impeachment não ficasse restrito apenas aos casos de traição e suborno. Seria preciso estender a possibilidade de impeachment a uma série de outras condutas igualmente danosas ao sistema constitucional como um todo. Assim, defendem que a tipificação das condutas que configurariam os mencionados "outros crimes graves e contravenções" iria de encontro a este entendimento dos convencionais da Filadélfia. Isso seria confirmado pelo fato de que, desde a fundação, nenhuma legislatura teria tentado aprovar uma lei tipificando as impeachable offenses. Também sustentam que seria impossível antever todas as condutas que poderiam deflagrar um processo de impeachment, sendo desnecessário e absurdo envidar esforços legislativos para tanto (TRIBE; MATZ, 2018, p. 48-50).

Há, contudo, vozes minoritárias. É o caso, por exemplo, de Nikolas Bowie que contesta a visão segundo a qual as impeachable offenses não precisariam estar definidas previamente em textos legais. ${ }^{20}$ Recuperando a defesa feita por Benjamin Curtis durante o impeachment de Andrew Johnson, Bowie sustenta que Tribe e Matz, assim como a doutrina constitucional majoritária norte-americana, "estão errados ao concluírem que condenar alguém pela prática de uma conduta que era lícita ao tempo que foi praticada - isto é, condenar alguém por crimes graves sem o Direito - é consistente com o texto constitucional ou com o espírito da Constituição" (BOWIE, 2018, p. 63). ${ }^{21}$ Bowie afirma que o posicionamento da doutrina majoritária viola o princípio do rule of law, bem como a determinação constitucional que veda expressamente bill of attainder e ex post facto laws (Artigo I, Seção 9, Cláusula 3, da Constituição norte-americana).

À luz do debate norte-americano do impeachment, há quem sustente que, no Brasil, dever-se-ia adotar uma posição semelhante. É o caso, por exemplo, de Paulo Brosssard (1992) e de Rafael Mafei Rabelo Queiroz (2017, p. 220-245) que afirmam que uma lei tal como a exigida pelo artigo 85, parágrafo único, da Constituição de 1988, seria desnecessária, inadequada mesma à essência do impeachment e, até mesmo, convidativa à sua própria violação pelos atores políticos responsáveis pela condução do feito.

\footnotetext{
${ }^{20}$ Para uma recuperação da crítica de Nikolas Bowie, em língua portuguesa, Cf. MEGALI NETO, 2020b, p. 148172.

${ }^{21}$ Tradução livre de: "they are wrong to conclude that it is consistent with the text or spirit of the Constitution to convict someone for conduct that was lawful when it was done - that is, to convict someone of 'high Crimes' without law" (BOWIE, 2018, p. 63).
} 
No entanto, é preciso estar atento às distinções entre as tradições norte-americana e brasileira do impeachment, como ressaltado por Pedro Lessa ainda no julgamento do HC n. 4.091. Quando Story diz, em seus comentários à Constituição, que nem sempre é possível definir as impeachable offenses, é difícil imaginar que ele estava se referindo à tradição constitucional brasileira, ou a uma tradição constitucional que delegue à lei especial a tarefa de definir as condutas passíveis de deflagrar um processo de impeachment. Ao dizê-lo, é óbvio que ele se referia à Constituição norte-americana que, diferentemente das constituições brasileiras, não exige que as impeachable offenses sejam definidas por lei especial. Por isso, Story afirma que nem sempre é possível definir essas condutas previamente.

Se no caso norte-americano é o Congresso que define, caso a caso, as impeachable offenses, no Brasil, é a lei especial que sempre o fez e que ainda o faz. Por essa razão, para dizer com Pontes de Miranda (1967, p. 350), "é sem qualquer pertinência invocar-se o direito inglês, ou o direito dos Estados Unidos da América, para se resolverem questões sobre a responsabilidade política no Brasil. Crimes de responsabilidade, no Brasil, são apenas os crimes que a lei apresenta". Aliás, ao tempo do impeachment do então presidente da República Fernando Collor de Mello, o próprio STF reconheceu a distinção existente entre a tradição norte-americana e a brasileira do impeachment. ${ }^{22}$ Tais fatos confirmam a tese de que, no Brasil, desde a Constituição de 1891, os contornos do impeachment foram definidos pela atuação dos tribunais e pela teorização dos constitucionalistas (BAHIA; BACHA E SILVA; CATTONI DE OLIVEIRA, 2017, p. 25).

\section{CONSIDERAÇÕES FINAIS}

Como visto no decorrer deste trabalho, a jurisprudência do STF se firmou, logo no início do período republicano, no sentido da possibilidade do controle jurisdicional do processo de impeachment. Ao confirmar a tese de que na tradição republicana brasileira do impeachment os crimes de responsabilidade seriam figuras de natureza mista, isto é, em parte política e em parte jurídico-penal, o STF reconheceu sua competência para exercer o controle do devido processo legal do processo de impeachment sempre que houver alegação de lesão ou ameaça de lesão a direito, sendo-lhe vedado, contudo, apreciar o mérito das decisões proferidas pelas Casas congressuais. Referido entendimento também permitiu ao Tribunal reconhecer que, em virtude da natureza jurídica dessas infrações, seria competência da união federal definir os crimes de responsabilidade e estabelecer suas regras de processo e

\footnotetext{
${ }^{22}$ Sobre isso, Cf. BRASIL, 1996; MEGALI NETO, 2020a.
} 
julgamento, posto que, sob a Constituição de 1891, assim como se passa sob a Constituição de 1988, competia privativamente à união federal legislar sobre direito penal.

Referido entendimento não fora superado pelo STF no pós-1988. Durante a década de 1990, o tribunal reforçou o entendimento por ele consolidado nos anos de 1916 e 1918 . Na tentativa frustrada de impeachment do presidente José Sarney e no impeachment que resultou no afastamento do presidente Fernando Collor de Mello, o STF reforçou a natureza política e jurídico-penal do instituto, a competência da união federal para definir os crimes de responsabilidade e estabelecer suas regras de processo e julgamento, bem como sua competência, enquanto guardião da Constituição, para resguardar o devido processo legal do processo de impeachment.

Superava-se, assim, a doutrina do impeachment de Paulo Brossard (1992), que, àquele momento, compunha o Tribunal na condição de ministro e opunha-se ferrenhamente ao entendimento então consagrado pelo STF no julgamento dos mandados de segurança n. 20.941, n. 21.564, 21.623 e n. 21.689, ao defender a natureza estritamente política do impeachment e, em virtude disso, a completa impossibilidade de controle jurisdicional do procedimento observado no interior do Congresso Nacional. Há uma manifestação do próprio Paulo Brossard em seu voto no mandado de segurança n. 21.564 que ilustra o isolamento de sua concepção doutrinária a respeito do tema, já no início da década de 1990. Naquela oportunidade, disse o ministro, após, mais uma vez, suscitar a preliminar de ausência de jurisdição do STF para conhecer da matéria que:

\begin{abstract}
Se não tivesse ficado em solitária unidade nesta Corte, em clara divergência com a sabedoria nunca assaz louvada de seus preclaros membros, que tenho como meus mestres, não me teria demorado na reiteração do meu entendimento já enunciado, quando da apreciação do pedido de liminar, e que, respeitosamente, reitero. Aliás, ainda hoje pela manhã, considerando a minha posição dissidente, perguntei-me se não estaria errado no entendimento de que descabe ao Poder Judiciário imiscuir-se no exercício de função jurisdicional que a Constituição outorga privativamente a outro Poder. Refleti mais uma vez sobre a matéria, e, para desgosto meu, hei de permanecer no insulamento a que me vejo reduzido, tendo viva a preocupação de que a questão não está tanto em interferir aqui ou ali ou deixar de fazê-lo, mas, em uma vez ingressado nessa área estranha, onde e como parar, retroceder e retirar-se (BRASIL, 1996, p. 161).
\end{abstract}

A partir de então, vários foram os casos nos quais o STF declarou a inconstitucionalidade de dispositivos de constituições estaduais que disciplinavam o processo e julgamento do governador pela prática de crimes de responsabilidade em desacordo com o modelo federal do impeachment. Há também casos nos quais o Tribunal declarou a inconstitucionalidade de dispositivos de leis estaduais e dos regimentos internos de 
assembleias legislativas estaduais que divergiam do modelo federal do impeachment. ${ }^{23}$ Tudo isso sob o fundamento de que, na tradição republicana brasileira do impeachment, os crimes de responsabilidade são figuras de natureza política, mas também em parte jurídico-penal, razão pela qual compete privativamente à união federal legislar sobre a matéria, como atesta a súmula n. 722 do STF, posteriormente convertida na súmula vinculante n. 46.

No impeachment da presidenta Dilma Rousseff, novamente, o STF teve a oportunidade de reafirmar seu compromisso sobre a matéria. ${ }^{24}$ Aliás, essa inclusive foi uma das premissas do voto que lançou a divergência quando do julgamento da ADPF n. 378: manter, tanto quanto possível, os entendimentos já produzidos pelo Tribunal em relação ao impeachment do presidente da República. Manutenção essa que, por sua vez, deveria abranger até mesmo questões não centrais desses julgados, os chamados obiter dicta. Houve, portanto, um compromisso institucional firmado em torno dessa questão pelo STF. Como afirmado pelo próprio ministro Luís Roberto Barroso em seu voto na ADPF n. 378, tratando-se de impeachment do presidente da República, o STF fez opção de seguir até mesmo os fundamentos não vinculantes expostos pelo próprio Tribunal sobre a matéria. ${ }^{25}$

Dessa maneira, pode-se dizer que, “ao contrário da prática constitucional norteamericana, os contornos do Impeachment no nosso constitucionalismo sempre contou com a intervenção da jurisdição constitucional, instrumento apto a aparar as ilegalidades cometidas pelo Parlamento" (BAHIA; BACHA E SILVA; CATTONI DE OLIVEIRA, 2017, p. 25). À primeira vista, portanto, o STF, no exercício da sua função contramajoritária, seria capaz de fazer frente às maiorias políticas ocasionais e, dessa maneira, seria capaz de garantir que tudo ocorresse dentro dos limites constitucional e legalmente previstos. Evitar-se-ia, assim, a onipotência do Congresso Nacional em relação à presidência da República.

\footnotetext{
${ }^{23}$ Sobre isso, apenas a título de exemplo, Cf. BRASIL. Supremo Tribunal Federal. ADI n. 132. Rel. Min. Sepúlveda Pertence. Julgamento em: 30/04/2003. DJ: 30/05/2004; BRASIL. Supremo Tribunal Federal. ADI n. 834. Rel. Min. Sepúlveda Pertence. Julgamento em: 18/02/1999. DJ: 09/04/1999; BRASIL. Supremo Tribunal Federal. ADI n. 1.225. Rel. Min. Francisco Rezek. Julgamento em: 08/03/1995. DJ: 04/08/1995; BRASIL. Supremo Tribunal Federal. ADI n. 1.628. Rel. Min. Eros Grau. Julgamento em: 10/08/2006. DJ: 24/11/2006; BRASIL. Supremo Tribunal Federal. ADI n. 1.879. Rel. Min. Joaquim Barbosa. Julgamento em: 17/11/2004. DJ: 11/03/2005; BRASIL. Supremo Tribunal Federal. ADI-MC n. 1.890. Rel. Min. Carlos Velloso. Julgamento em: 10/12/1998. DJ: 19/09/2003; BRASIL. Supremo Tribunal Federal. ADI n. 1.901. Rel. Min. Ilmar Galvão. Julgamento em: 03/02/2003. Julgamento em: 09/05/2003; BRASIL. Supremo Tribunal Federal. ADI n. 2.050. Rel. Min. Maurício Corrêa. Julgamento em: 03/03/2004. DJ: 02/04/2004; BRASIL. Supremo Tribunal Federal. ADI n. 2.220. Rel. Min. Cármen Lúcia. Julgamento em: 16/11/2011. DJe: 07/12/2011; BRASIL. Supremo Tribunal Federal. ADI-MC n. 2.235. Rel. Min. Octavio Gallotti. Julgamento em: 29/06/2000. DJ: 07/05/2004; BRASIL. Supremo Tribunal Federal. ADI n. 2.592. Rel. Min. Sydney Sanches. Julgamento em: 23/04/2003. DJ: 23/05/2003; BRASIL. Supremo Tribunal Federal. ADI n. 4.190. Rel. Min. Celso de Mello. Julgamento em: 10/03/2010. DJe: $11 / 06 / 2010$.

${ }^{24}$ Para uma recuperação da atuação do STF no caso Dilma Rousseff, Cf. MEGALI NETO, 2020a.

${ }^{25}$ Sobre isso, Cf. Luís Roberto Barroso, voto na ADPF n. 378, p. 159-166.
} 
Portanto, nos termos da jurisprudência historicamente consolidada do STF em relação à matéria, pode-se dizer, em alusão a George Mason (FARRAND, 1911, 65) quando dos debates da elaboração da Constituição norte-americana, que, tratando-se de impeachment, no Brasil, nenhuma pessoa ou instituição está acima do Direito. Com isso, não se quer dizer, contudo, que todo e qualquer processo de impeachment deflagrado no país será por si só constitucional e legal.

Antes disso, acredita-se que as aqui denominadas características distintivas dos crimes de responsabilidade na tradição republicana brasileira do impeachment se apresentam como importantes ferramentas para se fazer frente a possíveis arroubos majoritários que pretendam destituir da presidência da República um presidente democraticamente eleito em desrespeito às exigências do devido processo legal. Ao mesmo tempo, também fornecem fundamentos para a crítica que pode e deve ser direcionada ao STF quando, na hipótese de eventual processo político de responsabilização que transcorra às margens das exigências constitucionais e legais que disciplinam a matéria, referido Tribunal decida por não decidir ou simplesmente lave as suas mãos em relação à forma pela qual as maiorias políticas do Congresso Nacional pretendam conduzir um processo tal como este.

\section{REFERÊNCIAS BIBLIOGRÁFICAS}

BAHIA, Alexandre Melo Franco; BACHA E SILVA, Diogo; CATTONI DE OLIVEIRA, Marcelo Andrade. Os contornos do impeachment no Estado Democrático de Direito: historicidade e natureza da responsabilização jurídicopolítica no presidencialismo brasileiro. In. O impeachment e o Supremo Tribunal Federal: história e teoria constitucional brasileira. 2. ed. Florianópolis: Empório do Direito, 2017, p. 16-32.

BERGER, Raoul. Impeachment: the constitutional problems. Cambridge: Harvard University, 1973.

BILLIAS, George. American Constitutionalism Heard Round the World, 1776-1989: A Global Perspective. New York: New York University Press, 2009.
BLACK, Charles. Impeachment: a handbook. New Haven: Yale University Press, 1974.

BOWIE. Nikolas. High crimes without law. In. Harvard Law Review, v. 132, n. 3, dez. 2018, p. 59-77.

BRASIL. Supremo Tribunal Federal. Impeachment: Jurisprudência. Brasília: Imprensa Nacional, 1996.

CATTONI DE OLIVEIRA, Marcelo Andrade. Contribuições para uma teoria crítica da constituição. Belo Horizonte: Arraes, 2017.

CRETELLA JÚNIOR, José. Do impeachment no Direito brasileiro. São Paulo: Revista dos Tribunais, 1992. 
CRUZ, Álvaro Ricardo de. Jurisdição constitucional democrática. Belo Horizonte: Del Rey, 2004.

FALCÃO, Denise de Carvalho. O impeachment e suas características atuais: possibilidade de controle judicial. 2002. Dissertação de Mestrado, 2002. Dissertação (Mestrado em Direito). Faculdade de Direito da Universidade Federal de Minas Gerais, 2002.

FARRAND, Max. The Records of the Federal Convention of 1787. v. II. New Haven: Yale University Press, 1911.

GERHARDT, Michael. Putting the Law of Impeachment in Perspective. In. Saint Louis University Law Review, v. 43, n. 905, 1999, p. 905-930.

GERHARDT, Michael J. Impeachment: what everyone needs to know. Oxford: Oxford University Press, 2018.

HABERMAS, Jürgen. Constitutional Democracy: A paradoxical union of contradictory principles? In. Political Theory, 29 (6), 2001, p. 766-781.

HAMILTON, Alexander; MADISON, James Madison; JAY, John. The Federalist Papers. Oxford: Oxford University Press, 2008.

HORBACH, Carlos Bastide. Memória jurisprudencial: Ministro Pedro Lessa. Brasília: Supremo Tribunal Federal, 2007.

HORTA, Raul Machado. Direito constitucional. 4. ed. Belo Horizonte: Del Rey, 2003.

LESSA, Pedro. Do poder judiciário. Brasília: Senado Federal, Ed. fac-similar, 2003.

LEVINSON, Sanford. An argument open to all: reading The Federalist in the
Twenty-First century. New Haven: Yale University Press, 2015.

LYNCH, Christian Edward Cyril. O caminho para Washington passa por Buenos Aires: a recepção do conceito argentino do estado de sítio e seu papel na construção da República brasileira (18901898). In. Revista brasileira de Ciências Sociais, v. 27, n. 78, 2012, p.149-169.

MEGALI NETO, Almir. Controle jurisdicional do processo de impeachment: o impeachment da presidenta Dilma Rousseff perante o Supremo Tribunal Federal. 2020. Dissertação de Mestrado, 2020. Dissertação (Mestrado em Direito). Faculdade de Direito da Universidade Federal de Minas Gerais, 2020a.

MEGALI NETO, Almir. Impeachment, direito e política: lições a partir do caso Andrew Johnson. In. Revista Digital Constituição e Garantia de Direitos (UFRN), v. 13, p. 148-172, 2020b.

MEYER, Emilio Peluso Neder. Um processo de desmistificação: compreendendo criticamente o constitucionalismo estadunidense. In. Revista Direito Público, v. 15, p. 9-32, 2018.

MEYER, Emilio Peluso Neder. Repensando o Direito Constitucional Comparado no Brasil. In. Revista de Investigações Constitucionais, v. 6, p. 479-502, 2019.

PÉREZ-LIÑÁM, Aníbal. Presidential impeachment and new political instability in Latin America. Cambridge: Cambridge University, 2007.

PINTO, Paulo Brossard de Souza. O impeachment: aspectos da responsabilidade política do presidente da república. 3. ed. São Paulo: Saraiva, 1992. 
PONTES DE MIRANDA, Francisco Cavalcanti. Comentários à Constituição de 1967. Tomo III. São Paulo: Revista dos Tribunais, 1967.

QUEIROZ, Rafael Mafei Rabelo. A natureza jurídica dos crimes de responsabilidade presidencial no direito Brasileiro: Lições a partir do impeachment de Dilma Rousseff. In. Revista Eletrônica de Direito Público, v. 4, n. 2, 2017, p. 220-245.

RODRIGUES. Leda Boechat. História do Supremo Tribunal Federal. Vol. III. Doutrina Brasileira do Habeas Corpus (1910-1926). Rio de Janeiro: Civilização Brasileira, 1965.

STORY, Joseph. Commentaries on the Constitution of the United States; with a preliminary review of the constitutional history of the colonies and the states, before the adoption of the Constitution. v. II. Boston: Hilliard, Gray and Company, 1833.

STRECK, Lenio Luiz. Jurisdição constitucional. 5. ed. Rio de Janeiro: Forense, 2018.

SUNSTEIN, Cass. Impeachment: a citizens guide. Harvard University Press, 2017.

TRIBE, Laurence; MATZ, Joshua. To end a presidency: the power of impeachment. New York: Basic Books, 2018.

VIEIRA, José Ribas; CAMARGO, Margarida Lacombe. O impeachment e o seu desenho institucional conflitivo. In. Jota, 2016. Disponível em: $<$ https://www.jota.info/opiniao-eanalise/artigos/o-impeachment-e-o-seudesenho-institucional-conflitivo20012016>. Acesso em: 17 ago. 2017.

\title{
THE DISTINCTIVE CHARACTERISTICS OF THE IMPEACHABLE OFFENSES IN THE BRAZILIAN REPUBLICAN TRADITION OF THE IMPEACHEMET
}

\author{
Almir Megali Neto
}

How to cite this article: SILVA, Marco Antônio de Almeida; BARROS, Laura Ribeiro. Governança metropolitana e gestão de crises no contexto da pandemia da COVID-19: uma revisão de literatura. Revista de Ciências do Estado. Belo Horizonte: v. 6, n. 1, e25184. ISSN: 2525-8036.

\begin{abstract}
Old Republic between the American and Brazilian traditions of impeachment. As the guiding thread of this discussion, will be utilized the judgments handed down by the Brazilian Supreme Court in the judgment of the habeas corpus n. 4.091 and of the habeas corpus n. 4.116, respectively, in 1916 and 1918. In the first, the Court recognizes the possibility of judicial review of the impeachment process. In the second, the Court establishes the understanding that the federal union is exclusively responsible for legislate about impeachable offenses in Brazil. In both cases, against the backdrop of the political and legal-criminal nature of the impeachment in Brazilian Constitutional Law. As this is an eminently bibliographic research, the methodology used was the literature review.
\end{abstract}

Keywords: Brazil. United States of America. Impeachment. Juridical nature of the impeachable offenses. 